\title{
OBSERVAÇÃO DO “USUÁRIO/LEITOR” NA INTERAÇÃO COM OS RECURSOS DE REVISTA DIGITAL DESENVOLVIDA PARA TABLETS
}

\author{
Denize Roma de Barros Galvão \\ Centro Universitário Senac - São Paulo \\ deroma@terra.com.br
}

\begin{abstract}
Resumo
Esse artigo relata o resultado de um estudo piloto desenvolvido no contexto de uma pesquisa de doutorado que tem como problema fundamental investigar a convergência da mídia impressa para a digital nos projetos editoriais de revistas desenvolvidas para os tablets. Este estudo teve como foco a observação do "usuário/leitor," buscando compreender como se dá a interação com os recursos das revistas digitais nos tablets. Este levantamento observa o "manuseio" da revista impressa e de sua versão para tablets buscando analisar as formas como o leitor interage na migração do analógico para o digital. O propósito fundamental desta investigação é a compreensão da apropriação que o usuário faz dos projetos gráficos desenvolvidos para os tablets.
\end{abstract}

\section{Palavras-chave}

Design editorial, convergência de mídias, revistas digitais, publicações digitais

\begin{abstract}
This article reports the results of a pilot study developed in the context of a Ph.D research whose fundamental problem is to investigate the convergence of print to digital publishing projects in magazines designed for tablets. This study focused on watching the "user/reader," aiming to understand how he interacts with digital magazines features on tablets. This survey observes the "handling" of the printed magazine and of its tablet version seeking to analyze the ways in which the reader interacts in the migration from analogue to digital. The basic purpose of this investigation is to understand the appropriation that the user makes of the graphic design developed for tablets.
\end{abstract}

\section{Key words}

Editorial design, media convergence, digital magazines, digital publishing 


\section{Introdução. Caracterização geral da pesquisa}

A pesquisa aqui apresentada é parte integrante de uma trabalho de doutorado que tem como problema fundamental investigar a convergência da mídia impressa para a digital nos projetos editoriais de revistas desenvolvidos para tablets. $\mathrm{O}$ trabalho apresenta o resultado de um estudo piloto desenvolvido neste contexto, focando no usuário "leitor" e observando como se dá a interação com os recursos das revistas digitais nos tablets. A questão fundamental do doutorado indaga quais são as possibilidades adicionais de expressão que se oferecem ao design gráfico de revistas brasileiras originalmente projetadas para o meio impresso em suas edições digitais desenvolvidas para tablets, e como estes novos recursos de linguagem poderiam ser sistematizados e classificados em categorias taxonômicas.

Os princípios do design tradicionalmente utilizados para conceber a composição de página pressupõem uma leitura estática, característica do impresso, em que a página, depois de composta, não muda de orientação, e seus elementos não podem ser alterados. Estes parâmetros necessitam ser revistos para contemplar sua migração para os tablets. Há a necessidade de ajustes nestes procedimentos para que projetos de publicações seriadas destinados para os tablets atinjam todo o seu potencial de interação com o usuário possibilitando uma maior leiturabilidade.

Não se trata apenas de uma conversão automática viabilizada por software ou por recursos de programação, o foco nesta pesquisa não é a tecnologia. O que se pretende com este estudo é enfatizar o papel do designer e a necessidade de investigar os parâmetros e os fundamentos do design para a criação de novas estruturas de organização da informação, agora viabilizada em dispositivos de leitura eletrônicos.

Derivando deste problema, podemos identificar alguns subproblemas que pertencem a esse universo, como, por exemplo: o que deve ser adaptado na estrutura de grid para facilitar a interação do leitor, e ainda assim manter a identidade da publicação? O grid na publicação digital ainda tem a mesma função que exercia na mídia impressa? O usuário consegue identificar os novos recursos disponíveis no dispositivos eletrônicos de leitura? As matérias da revista são localizadas com facilidade pelo usuário? Os ícones indicadores de navegabilidade são facilmente compreendidos e decodificados?

Estas questões tem rondado o mercado editorial e o ambiente acadêmico dos cursos de design. Justifica-se a necessidade de um estudo sobre o design gráfico e a visualização de notícias destas publicações.

Problemáticas anteriormente pertinentes a web designers agora fazem parte do universo de designers que atuam no mercado editorial. Os recursos multimidiáticos agora possíveis em dispositivos de leitura remontam à experiência do surgimento da web, momento no qual os designers também foram desafiados a projetar para ambientes dinâmicos. Neste sentido, iremos investigar os conceitos abordados por Roger Black (1997) em seu livro Web sites que funcionam, onde ele afirma que "O design não deve ser uma mera decoração; ele precisa comunicar. O leitor nunca deve ter de passar por florestas de botões para obter simples notícias" (BLACK, 1997, p.43). Neste livro, o autor aborda questões que serão de grande relevância para este trabalho, como, por exemplo, a importância de estruturar a navegação, a tipografia para leitura na tela e a utilização de imagens em movimento. 
Em Do códice ao monitor: a trajetória do escrito, Roger Chartier questiona as novas maneiras de ler e os suportes e a forma de transmitir o texto escrito, segundo o autor,

Ler num monitor não é o mesmo que ler num códice. Se é verdade que abre possibilidades novas e imensas, a representação eletrônica dos textos modifica totalmente a condição destes: à materialidade do livro, ela substitui a imaterialidade de textos sem lugar próprio; às relações de contigüidade estabelecidas no objeto impresso, ela opõe a livre composição de fragmentos indefinidamente manipuláveis; à apreensão imediata da totalidade da obra, viabilizada pelo objeto que a contém, ela faz suceder a navegação de muito longo curso, por arquipélagos textuais sem beira nem limites. Essas mutações comandam, inevitável e imperativamente, novas maneiras de ler, novas relações com o escrito, novas técnicas intelectuais. (CHARTIER, 1994, $s p)$

Em texto mais recente, Gui Bonsiepe (2011), em seu livro Design, cultura e sociedade, menciona a problemática do design de informação no capítulo "Cognição e Design - o Papel da Visualização para a Socialização dos Conhecimentos", onde questiona o papel do designer neste novo cenário. Segundo Bonsiepe,

Em virtude do desenvolvimento tecnológico dos meios digitais, abriram-se novas possibilidades de atuação do design. A apresentação interativa de informações oferece um desafio para o design gráfico tradicional [...] Porém, interação no sentido mais restrito se refere hoje à apresentação de informação por meio de documentos digitais. [...]. Limito-me a duas constantes. Por um lado, temos o cuidado com as características do usuário e, por outro, o cuidado com a qualidade formal-estética. (BONSIEPE, 2011. p.87)

O autor define o enfoque do design de interfaces digitais para divulgação de informação. Desta forma, convoca os profissionais de design a assumirem seu papel neste novo cenário.

Os designers poderiam intervir exatamente nesse ponto, pois eles dominam - ou deveriam dominar - os meios para reduzir a complexidade cognitiva e contribuir para apresentar informação de forma útil, desenvolvendo uma interface adequada entre a informação e o usuário/leitor. (BONSIEPE, 2011. p.89)

Observa-se nesta citação que Bonsiepe coloca o usuário/leitor como alvo, destinatário final da informação. Pode-se observar igualmente a preocupação com a "qualidade formal-estética", característica da atuação do designer. Observar como o usuário interage com a interface desenvolvida é fundamental para perceber se o objetivo da publicação foi alcançado.

Problema específico para este recorte da pesquisa é a observação do usuário. Como o "usuário/leitor" interage com os recursos das revistas digitais disponíveis nos tablets de leitura? Como o leitor navega pelas seções/matérias da revista? 
A percepção de como o usuário interage com a revista concebida para o tablet é fundamental para direcionar o designer a buscar soluções que sejam mais adequadas ao projeto.

A observação participativa permite uma abordagem qualitativa que traz informações fundamentais para a pesquisa visando direcionar os projetos de publicações digitais a melhorar a navegabilidade, hierarquia de informação e exploração dos recursos adequados para reter o interesse do leitor.

Na mídia impressa convencional, a revista é estática: uma vez composta a página, esta é permanente e não se altera. O leitor se adapta ao layout proposto pelo designer. Já nas revistas desenvolvidas para os tablets existe a possibilidade de visualização de suas páginas no sentido vertical e/ou horizontal, utilização de vídeo, ampliação do tamanho da letra, alteração das imagens, rotação de elementos tridimensionais, visualização panorâmica de ambientes e paisagens, entre outros. Este tipo de interação nas revistas convencionais não é possível.

O experimento aqui relatado teve como objetivo de observar o "manuseio" da revista impressa e de sua versão para tablets, buscando analisar as formas como o leitor interage na migração do analógico para o digital. Diante do acima exposto, podemos pressupor que este cenário vai além da questão tecnológica, mudam os hábitos de leitura.

\section{Procedimentos Metodológicos}

O estudo piloto utilizou método de natureza qualitativa na abordagem. Foram utilizadas duas técnicas: observação participante e entrevistas semi-estruturadas em profundidade. A intenção foi perceber a possibilidade de categorias comuns que remetessem o discurso à real utilização.

\subsection{Estratégias adotadas para aplicação do método}

Para este estudo piloto, que teve como finalidade averiguar a eficiência deste procedimento na investigação do comportamento do leitor, foram selecionadas três pessoas.

Estabeleceu-se como critério de seleção que os indivíduos fossem leitores não especializados, ou seja, não poderiam ser designers, editores ou jornalistas para não "contaminar" as apreciações sobre a publicação com práticas profissionais. A faixa etária estipulada ficou em torno de 35 a 65 anos, classe social B (informações de público alvo extraídas do media kit da editora Abril para a revista Veja).

Os entrevistados foram abordados e informados quanto ao propósito da pesquisa como parte integrante de um trabalho para doutorado e receberam o Termo de Consentimento Livre e Esclarecido de Pesquisa disponibilizado no portal do Centro Universitário Senac.

As observações e entrevistas aconteceram em lugar tranquilo e confortável, sem a interferência de terceiros. Foi realizada a filmagem dos entrevistados, focando apenas no manuseio das publicações, sem revelar suas identidades.

Buscou-se, neste estudo, utilizar revista semanal de grande circulação e reconhecimento público, a revista selecionada foi a Veja da Editora Abril. O exemplar utilizado foi da edição número 2340 de 25 de setembro de 2013 (figura 1). 


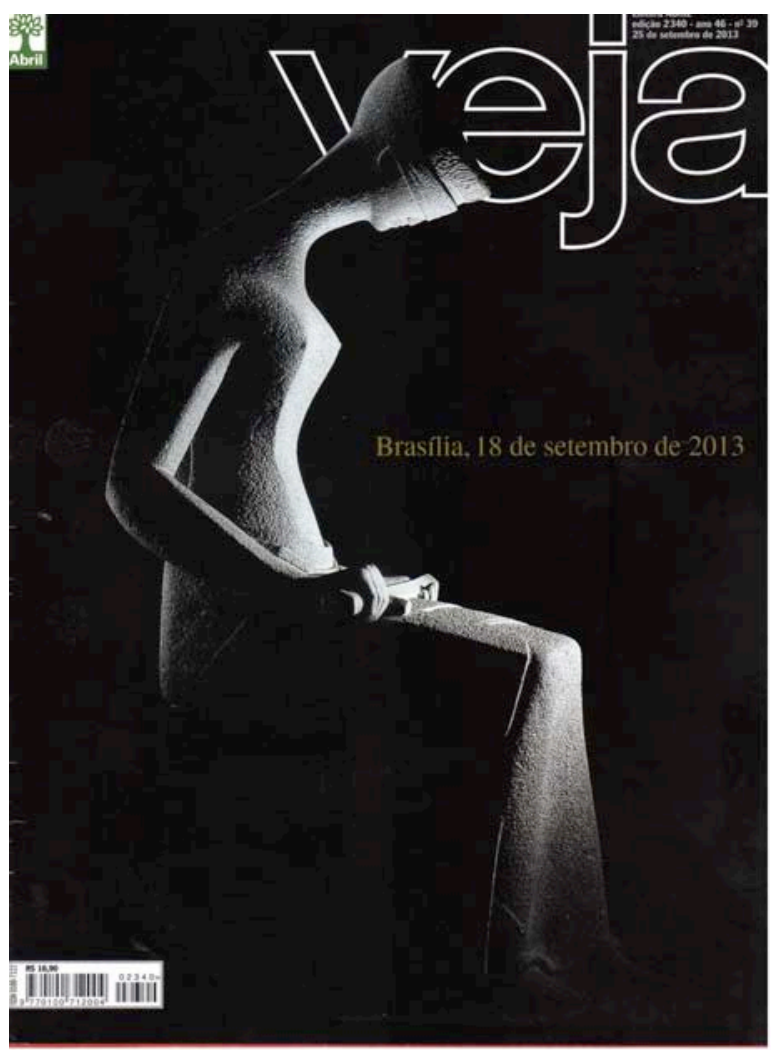

Figura 1 - Foto da capa da revista utilizada na pesquisa. Foto elaborada pela autora, com base na pesquisa realizada.

Para os três entrevistados, em um primeiro momento foi apresentada a edição da revista digital no tablet, e depois a mesma edição impressa. Não foi estipulado tempo de leitura, permitindo que os usuários ficassem à vontade e seguissem seu ritmo de acordo com seus interesses.

Foram observados o tempo de leitura, a exploração dos recursos, a facilidade/dificuldade de interagir com a interface, e a navegação pelas seções/matérias da revista.

Após a leitura da revista nas duas mídias, digital e impressa, foi feita uma entrevista, buscando depreender as impressões dos usuários sobre experiência vivenciada.

\section{Observação dos usuários e resultados}

Para manter o sigilo dos entrevistados, seus nomes não serão citados, serão apenas informadas, no quadro 1, algumas características determinantes para a pesquisa. 


\begin{tabular}{|l|l|l|l|l|l|}
\hline Leitor & Idade & Sexo & Profissão & $\begin{array}{l}\text { Já leu revistas no } \\
\text { tablet antes? }\end{array}$ & $\begin{array}{l}\text { Principal forma de navegação } \\
\text { observada }\end{array}$ \\
\hline A & 38 & Feminino & $\begin{array}{l}\text { técnica de } \\
\text { desenvolvimento } \\
\text { profissional }\end{array}$ & sim & $\begin{array}{l}\text { Fez rolagem das páginas no } \\
\text { início. Utilizou sumário da } \\
\text { revista. }\end{array}$ \\
\hline B & 66 & Masculino & $\begin{array}{l}\text { Engenheiro } \\
\text { químico } \\
\text { aposentado }\end{array}$ & não & $\begin{array}{l}\text { Fez rolagem das páginas de } \\
\text { maneira linear. Não utilizou } \\
\text { sumário ou índice }\end{array}$ \\
\hline C & 42 & Feminino & $\begin{array}{l}\text { Gerente de } \\
\text { treinamento de } \\
\text { uma ONG }\end{array}$ & não & $\begin{array}{l}\text { Utilizou barra de navegação } \\
\text { localizada na base da tela do } \\
\text { dispositivo. }\end{array}$ \\
\hline
\end{tabular}

Quadro 1 - Quadro de resumo das principais características dos entrevistados. Elaborada pela autora, com base na pesquisa realizada.

\subsection{Leitora A}

A entrevista com a Leitora A durou aproximadamente 33 minutos. Deste tempo, 19 minutos foram dedicados à leitura da revista no tablet, 7 minutos à leitura da revista impressa, e no tempo restante conversou-se sobre a experiência de visualizar a mesma publicação em mídias diferentes.

Conforme mencionado anteriormente, a revista foi lida primeiramente no tablet, e a Leitora A demonstrou certa habilidade com o dispositivo. Ao abrir a revista, não comentou a animação existente na capa desta edição. Passou rapidamente pelos anúncios e observou atentamente o "Guia de navegação da revista" (única entrevistada a observar esta página, que é fundamental para decodificar os ícones que sugerem a interatividade da publicação, figura 2).

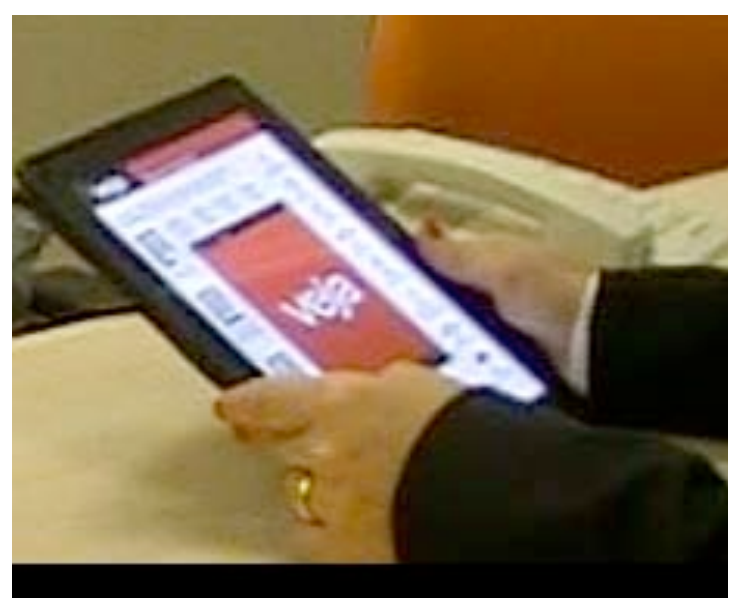

Figura 2 - Observação do "Guia de navegação" da revista. Imagem extraída do vídeo da entrevista. Elaborada pela autora, com base na pesquisa realizada.

Durante a maior parte do tempo, a Leitora A navegou pela publicação utilizando o sumário da revista, escolhendo as matérias a serem visualizadas de acordo com seu interesse pelo tema (figuras 3 e 4). 


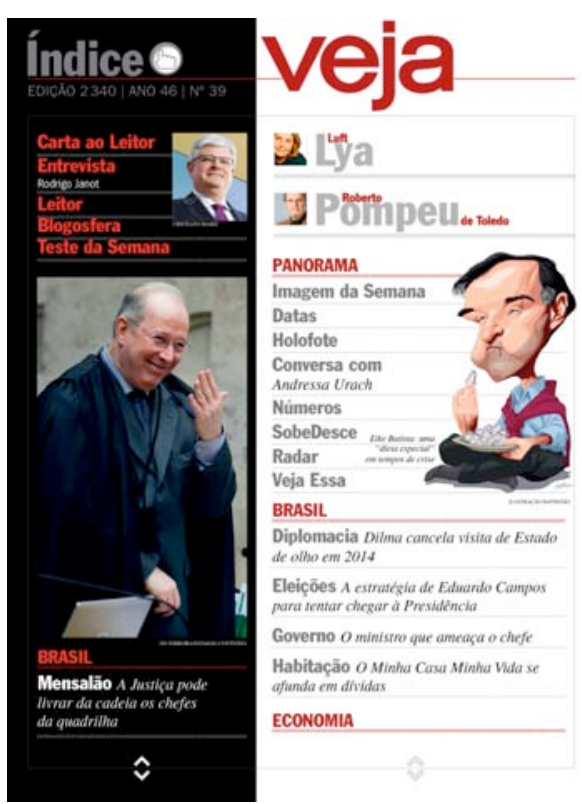

Figura 3 - Página do sumário da revista com link para todas as matérias. Foto elaborada pela autora, com base na pesquisa realizada.

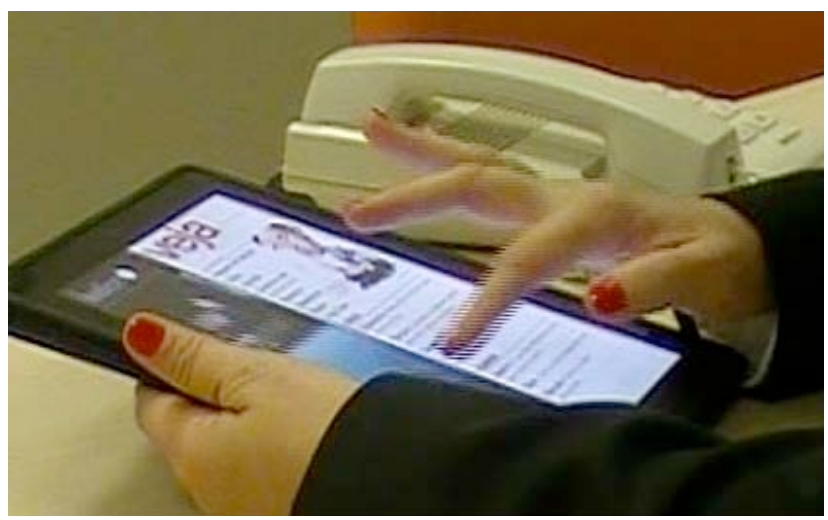

Figura 4 - Utilização do sumário da revista. Imagem extraída do vídeo da entrevista. Elaborada pela autora, com base na pesquisa realizada.

A leitora explorou os recursos do dispositivo, fazendo rolagem nos boxes de texto, ampliando as imagens e textos, utilizando o movimento de pinça, e visualizando vídeos disponibilizados na publicação. Em alguns momentos, rolou as páginas de trás para frente, atitude repetida posteriormente na leitura da revista impressa.

A leitura no impresso foi mais rápida e mais linear. Apenas em poucos momentos a Leitora A folheou as páginas de trás para frente. Não utilizou o sumário na revista impressa, mas observou uma matéria sobre questões de saúde que não havia encontrado na versão digital.

Ao terminar as leituras, relatou que já tinha lido outras revistas no tablet, mas a experiência foi interessante pois nunca tinha comparado as duas mídias.

Algumas colocações feitas pela leitora:

"No impresso você é obrigado a passar pelas folhas[...] no digital, como eu posso escolher, eu vou direto para a matéria que me interessa."

"... as fotos ficam mais bonitas no digital."

"Para quem não tem conhecimento de manusear [o tablet], é um pouco difícil no início, mas depois que você descobre quais são os caminhos fica muito fácil." 
"Manusear uma revista [impressa] ainda é muito gostoso."

"Legal levar o jornal, revista, ou o que mais quiser para onde for." [fazendo referência a reunir todas as modalidades de leitura no tablet]

\subsection{Leitor B}

A entrevista com o Leitor B durou aproximadamente 27 minutos. Deste tempo, 14 minutos foram dedicados à leitura da revista no tablet e 7 minutos à revista impressa. No tempo restante, conversou-se sobre a experiência de visualizar a mesma publicação em mídias diferentes.

Apesar de possuir um tablet, o leitor afirmou que não costuma utilizá-lo para leitura de livros ou revistas, pois seu uso fica concentrado nos e-mails. Teve dificuldade inicial no manuseio da revista como no movimento de virar as páginas. Como a leitora anterior, também não comentou a animação existente na capa, e passou rapidamente pelos anúncios. Não observou o "Guia de navegação da revista" (figura 5), ignorando por completo suas informações.

Observou atentamente o sumário da revista, mas não fez uso dos links existentes para navegação. Durante todo o tempo de leitura folheou as páginas de maneira linear como se estivesse com material impresso nas mãos. Em alguns momentos, parava para ler mais atentamente alguma matéria, mas não fez rolagem de textos.

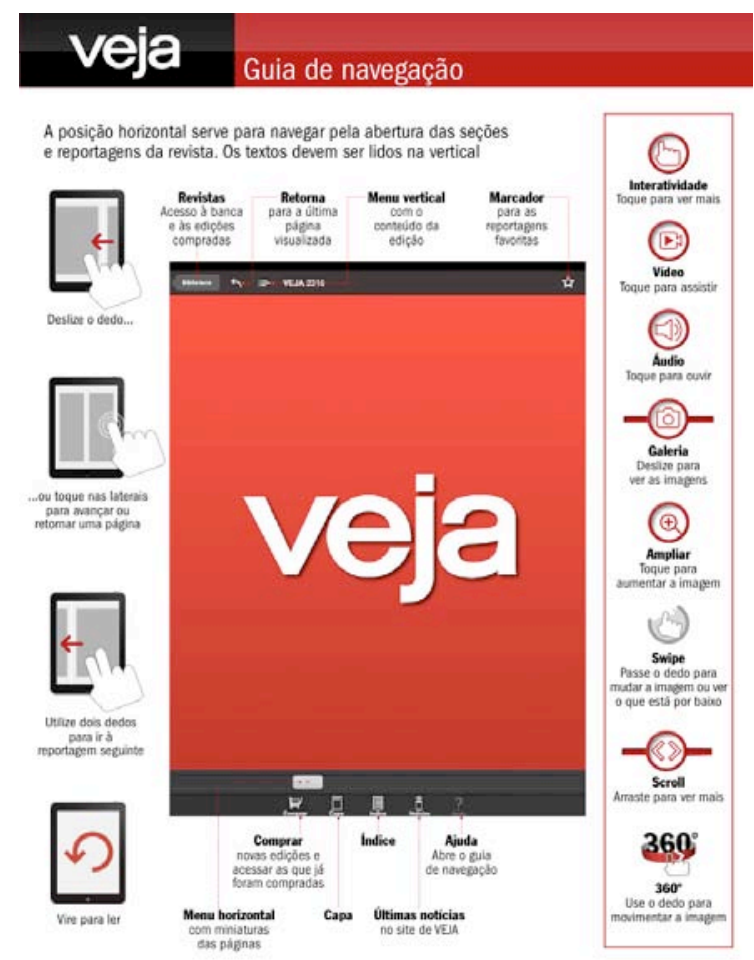

Figura 5 - Foto do Guia de navegação da revista. Foto elaborada pela autora, com base na pesquisa realizada. 
A leitura no impresso (figura 6) foi mais rápida e igualmente linear. O Leitor B não utilizou o sumário na revista impressa, fazendo a leitura na ordem em que as matérias apareciam na publicação. Analisando a experiência, o leitor relatou que o recurso que mais chamou sua atenção foi a utilização de vídeo para ilustrar as reportagens.

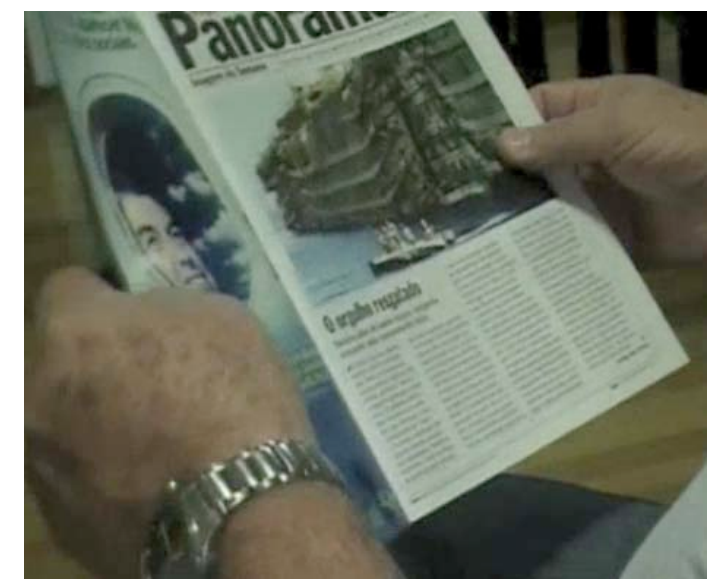

Figura 6 - Matéria da revista impressa possui vídeo na versão digital. Imagem extraída do vídeo da entrevista. Elaborada pela autora, com base na pesquisa realizada.

$\mathrm{O}$ Leitor $\mathrm{B}$ também relatou:

"Achei interessante a parte animada do vídeo, a revista não mostra isso, claro, é estática. $O$ navio ficando em pé assim..., eu já tinha visto uma imagem mas não tão completa como essa aí, fica interessante no iPad."

Sugeriu, ainda, que as propagandas também poderiam fazer uso de vídeo.

\subsection{Leitora C}

A entrevista com a Leitora $C$ durou 22 minutos. Deste tempo, 12 minutos foram dedicados à leitura da revista no tablet, e 3 minutos à revista impressa. No tempo restante, conversou-se sobre a experiência de visualizar a mesma publicação em mídias diferentes.

Apesar de possuir um tablet, a leitora informou que não costuma utilizá-lo para leitura de revistas, que tem apenas assinatura de jornal, e que seu uso fica concentrado na internet e games, utilizados pelos filhos. Como os leitores anteriores, também não comentou a animação da capa e passou rapidamente pelos anúncios. Não observou o "Guia de navegação da revista," ignorando por completo suas informações.

A Leitora C demonstrou habilidade na utilização do tablet enquanto equipamento, mas pouco conhecimento em sua utilização como dispositivo de leitura. Apesar de fazer rolagem de texto e buscar ampliação das imagens com o movimento de pinça, teve dificuldades iniciais no reconhecimento dos ícones que sinalizavam interatividade. Observou o sumário, mas não fez uso dos links para acessar as matérias. 

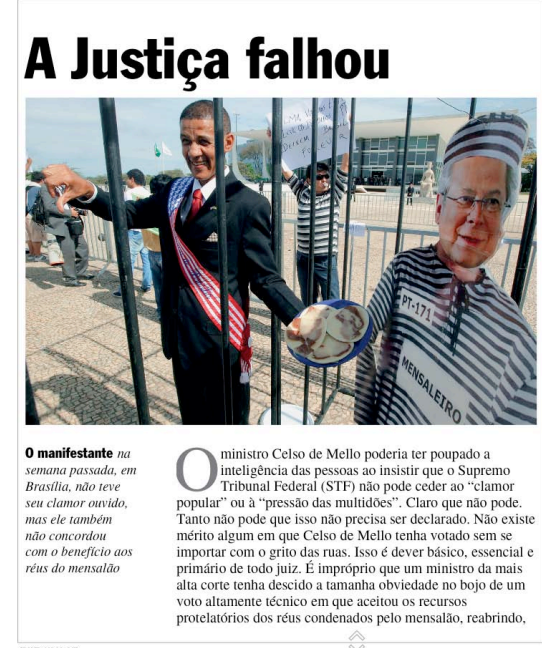

primário de todo juiz. É impróprio que um ministro da mais alta corte tenha descido a tamanha obviedade no bojo de um voto altamente técnico em que aceitou os recursos protelatórios dos réus condenados pelo mensalão, reabrindo,

primário de todo juiz. É impróprio que um ministro da mais

alta corte tenha descido a tamanha obviedade no bojo de um

voto altamente técnico em que aceitou os recursos

protelatórios dos réus condenados pelo mensalão, reabrindo,

Figura 7 - Matéria com rolagem de texto e detalhe do ícone no pé da página. Foto elaborada pela autora, com base na pesquisa realizada.

Ao tentar clicar no ícone que sinalizava rolagem de texto (localizado no pé da página, figura 7) descobriu o menu horizontal de navegação e passou a utilizá-lo para navegar pela revista (figura 8).

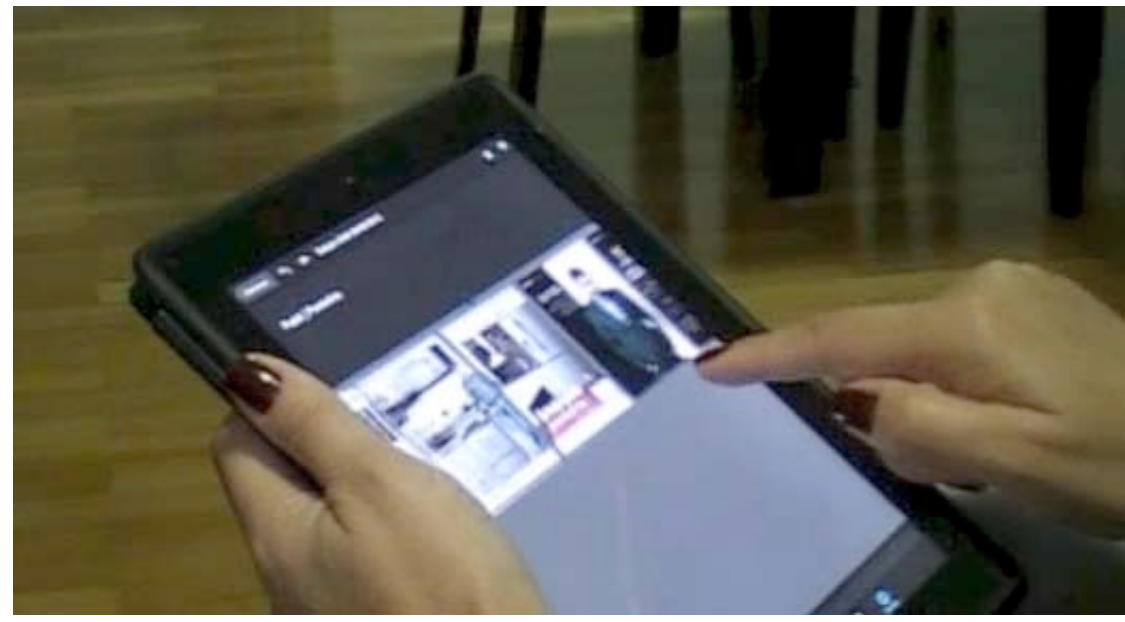

Figura 8 - Utilização do menu horizontal de leitura para navegar pela revista. Imagem extraída do vídeo da entrevista. Elaborada pela autora, com base na pesquisa realizada.

Com a prática exploratória pelos elementos da página, descobriu os ícones de interatividade, e passou a explorar todos os recursos sinalizados, como, por exemplo, vídeo e música (disponibilizado na seção de lançamentos de CDs) . 

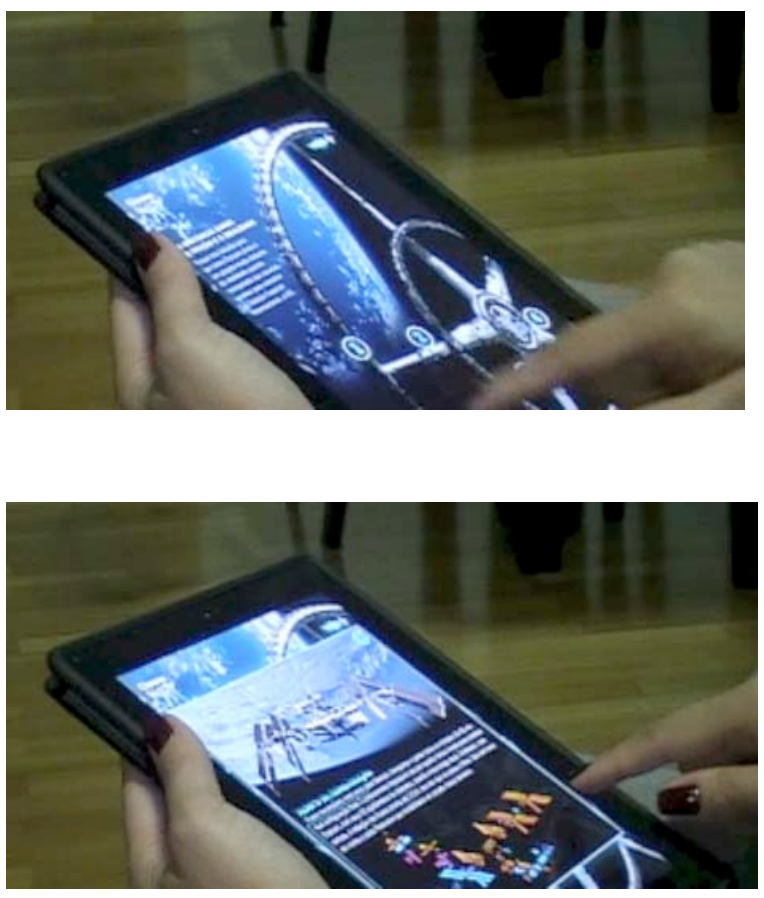

Figuras 9 e 10 - Utilização da interatividade em infográgicos. Imagem extraída do vídeo da entrevista. Elaborada pela autora, com base na pesquisa realizada.

A leitura da revista digital não seguiu uma sequência linear. Foi muito direcionada a interesses pessoais pelos assuntos tratados nas matérias e à exploração dos recursos interativos da publicação recém descobertos. Ao receber a revista impressa, não demonstrou interesse, alegando que, depois de conhecer os recursos de som e vídeo do tablet, o impresso parecia "sem graça, não vai tocar música..." Folheou a revista saltando as matérias, e por vezes de trás para frente.

Ao comentar a experiência, mencionou que a versão digital, por utilizar outros elementos, como o som, e o manuseio diferenciado com possibilidade de interação, torna a publicação mais interessante, e que não sabia que eram explorados tantos recursos nas revistas desenvolvidas para tablets. Questionou o posicionamento dos ícones de interatividade que por vezes confunde o leitor iniciante.

Algumas colocações da Leitora C:

"Digital dá mais vida ao conteúdo da matéria"

"A interação no tablet é muito interessante. Usar outros sentidos para ler no tablet como audição, visão, etc."

"as flechinhas embaixo confundem com a barra de ferramentas"

\section{Considerações Finais}

Pela observação dos usuários selecionados, foi possível perceber algumas características no manuseio desta revista. O tempo dedicado à leitura no tablet foi maior do que o dedicado à revista impressa nas três entrevistas. O conhecimento do conteúdo previamente apresentado no formato digital pode ter comprometido o interesse na publicação impressa. Sendo assim, em futuras abordagens, pretende-se 
fazer observações das mídias em momentos distintos ou utilizando edições diferenciadas.

Nem sempre os leitores utilizaram os recursos disponibilizados. A página destinada ao "Guia de navegação" se confunde com os anúncios e é pouco percebida e utilizada, o que prejudica o aproveitamento dos recursos inseridos na publicação. Será necessário questionar se a apresentação prévia dos ícones de indicação de interação e navegabilidade direcionariam o leitor, corrompendo os resultados da pesquisa.

Algumas escolhas de posicionamento e forma dos ícones de navegabilidade podem ser questionadas. Conforme observado em alguns casos, estes ícones não foram percebidos ou foram confundidos com botões, o que acabou atrapalhando a leitura e a exploração dos elementos que complementam a informação das matérias.

O sumário da revista (figura 3) possui link para todas as matérias da publicação e na observação realizada só foi explorado pela Leitora $A$, que já possuia experiência com leitura de revistas em tablets. Até ser formada uma cultura de leitores de publicações digitais em dispositivos eletrônicos, poderia-se argumentar a favor de estratégias para deixar clara a função desta página.

Para chegar a conclusões generalizáveis, será necessária uma amostragem maior, com mais indivíduos. Ainda assim, percebeu-se que esta técnica permite observar como efetivamente o usuário/leitor faz uso do produto desenvolvido pelo designer, configurando-se como relevante fonte de informação para o direcionamento de projetos que atendam às necessidades de comunicação.

\section{Referências}

BLACK , Roger. Web sites que funcionam. Califórnia: Adobe Press,1997.

BONSIEPE, Gui. Design, cultura e sociedade. São Paulo: Blucher, 2011.

CHARTIER, Roger. Do códice ao monitor: a trajetória do escrito. Estudos avançados, São Paulo, v. 8, n. 21, maio/ago. 1994. 